\title{
Elastic characterization of wood by Resonant Ultrasound Spectroscopy (RUS): a comprehensive study
}

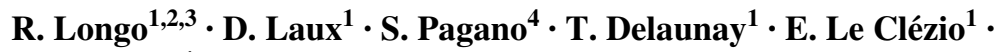 \\ O. Arnould ${ }^{4}$ (D)
}

\begin{abstract}
The main principle of Resonant Ultrasound Spectroscopy (RUS) measurement method is to excite a sample and to deduce its elastic constants from its free mechanical resonant frequencies. The goal of this paper is to propose an applica-tion of RUS in the case of wood cubic samples by: (1) using frequencies and mode shapes (or vibration patterns) of the free resonant modes in an iterative numerical procedure to solve the inverse problem for identifying components of the stiffness tensor of the sample's material, (2) finding the limits and optimizing the robustness of the identification procedure in the case of wood and (3) applying it to a large density range of wood samples. Specific continuous waves have been used as excita-tion signal in order to experimentally determine the free resonant frequencies and mode shapes of the sample in a faster way by means of Scanning Doppler Vibrom-eter measurements. Afterward, the stiffness tensor was derived by solving iteratively an inverse problem. The gain of using the mode shapes in the inverse identification procedure is demonstrated to be particularly necessary for wood, especially for pair-ing each measured frequency with its corresponding theoretically predicted one, as viscoelastic damping causes the resonant peaks to overlap and/or disappear. A sen-sitivity analysis of each elastic constant on the measured resonant frequencies has thus been performed. It shows that, in its current state of development, not all of the
\end{abstract}

O. Arnould

olivier.arnould@umontpellier.fr

1 IES, Univ. Montpellier, CNRS, Montpellier, France

2 Present Address: ESEO Group - GSII, Angers, France

3 LAUM, CNRS, Le Mans, France

4 LMGC, Univ. Montpellier, CNRS, Montpellier, France 
elastic constants can be identified robustly and a modified identification procedure is thus proposed. This modified procedure has been applied successfully to wood samples with a large density range, including softwood and hardwood, and particularly non-homogeneous wood species or with specific anatomical features.

\section{Introduction}

Material symmetries and mechanical behavior of some biological and geological materials (wood, bones, rock ...) are not well known so far. In particular, wood material is difficult to characterize due to its biological origin that induces anisotropic behavior, strong variability (especially within a tree), heterogeneity and sensitivity to moisture content, temperature and loading time (i.e., viscoelasticity). Wood is a natural composite that behaves approximately like an orthotropic material at the millimeter scale with eigendirections, or natural symmetry axes, that are almost parallel to the visible anatomical ones in the tree: radial $R(1)$, tangential $T(2)$ and longitudinal $L(3)$ in cylindrical coordinates. However, difficulties occur in determining the nine elastic independent components of its stiffness tensor $C$ (denoted $C_{i j}$ in Voigt (1928) notation where $C_{44}=C_{2323}, C_{55}=C_{1313}$ and $C_{66}=C_{1212}$ ), especially the off-diagonal terms that depend on the Poisson's ratios $v_{i j}$ (i.e., negative ratio of the transverse (passive) strain $\epsilon_{j j}$ and axial (active) strain $\epsilon_{i i}$ during a tensile test in the axial direction). This leads to underuse and/or misuse of this material. Predicting accurately its behavior for given environmental conditions is still an open question.

Several references in the literature focus on the measurements of parts of, or of the whole, stiffness tensor of wood using many samples (Bucur 2006; Dahl and Malo 2009; Garab et al. 2010; Gonçalves et al. 2011; Keunecke et al. 2008; Laghdir et al. 2008; Ozyhar et al. 2013b; Reiterer and Stanzl-Tschegg 2001). However, due to the natural variability, some inconsistencies may appear and efforts were made to develop methods implying the use of the smallest number of samples as possible to robustly identify all the elastic constants. Ideally, using only one sample is preferable and allows studying the natural variability. In this context, quasi-static measurements on a single sample of wood have been taken (Bruno and Poggialini 2005; Bruno et al. 2008; Majano-Majano et al. 2012; Seichepine 1980; Vorobyev et al. 2016). This method can be accurate for determining the Young's moduli and some of the Poisson's ratios, but is not so suitable for the determination of the shear moduli on a heterogenous material like wood, due mainly to a non-homogeneous stress field, and it is time-consuming (Hassel et al. 2009). Faster measurements can be obtained by using different techniques based on the measurement of ultrasonic wave velocities (Bucur 2006; Kohlhauser et al. 2009). Ultrasonic wave methods are largely employed for this kind of investigation, because they are cheap, easy to generate and to detect. They usually allow the determination of the diagonal terms of the elastic tensor on a unique parallelepipedic sample (Keunecke et al. 2007) but, except in some cases with a polyhedral (François et al. 1998; Gonçalves et al. 2014; Vázquez et al. 2015) or spherical sample (Bucur and Rasolofosaon 1998; El Mouridi et al. 2011), the method usually requires several samples, and/or coupling with other kinds of measurement, for the determination of off-diagonal terms (i.e., Poisson's 
ratios) (Bucur 2006; Dahmen et al. 2010; Gonçalves et al. 2011; Kohlhauser and Hellmich 2012). These methods require samples much larger than the wavelength, and this is not always possible to achieve for heterogeneous materials by scaling down the wavelength. Furthermore, for geometries with low aspect ratio, the relation between the elastic constants and the wave velocities is not so straightforward, especially for the transverse direction $(R, T)$. Moreover, these methods are less suitable for determining shear wave velocities in wood due to a high damping.

Acoustic measurements based on the free resonant frequencies of the sample are commonly used for measuring the viscoelastic properties of wood but usually for only one direction with samples having a high aspect ratio (Brancheriau and Baillères 2002; Brémaud et al. 2010; Obataya et al. 2000; Yoshihara 2012). Reducing the aspect ratio of the sample leads to Resonant Ultrasound Spectroscopy (RUS) methods that could offer a good alternative because the determination of the full stiffness tensor could be obtained from only one sample thanks to the measurement of its free resonant frequencies. It has already been successfully applied to low damping isotropic or anisotropic materials (Delaunay et al. 2008; Laux et al. 2006; Migliori et al. 1993; Visscher et al. 1991), but its application becomes more complex when testing materials of unknown symmetry and/or with high attenuation (Bernard et al. 2014, 2015; Farzbod and Hurley 2012; Grimsel 1998). It was first experimentally used on wood by Schubert et al. (2006) but only for the determination of one shear modulus by using the two lowest resonance frequencies (Grimsel 1998). A first application of RUS measurements on a wood sample for determining all the elastic constant has been proposed by Longo et al. (2012). In this cited work, the elastic tensor of a cubic sample of beech (Fagus sylvatica L.) was estimated by minimizing the difference between measured and simulated resonant frequencies. This method has been extended and compared to quasi-static measurements in Vorobyev et al. (2016) on cubic samples of oak.

In the present paper, the already proposed method has been substantially extended. The main improvements concerned the use of a specific continuous excitation wave and the extension of Laser Doppler Vibrometer to the scanning of the sample surface (SLDV) allowing the experimental determination of the mode shapes (or vibration patterns) associated with each measured free resonant frequencies. The gain of using the mode shapes in the inverse identification procedure is demonstrated to be particularly necessary for wood, especially for pairing each measured frequency with its corresponding theoretically predicted one, as viscoelastic damping causes the resonant peaks to overlap and/or disappear. This new information has been included in a modified inverse identification procedure that has been tested on the same beech sample as the previous study (Longo et al. 2012). A sensitivity analysis of each elastic constant on the measured resonant frequencies has thus been performed. It shows that, in its current state of development, not all of the elastic constants can be identified robustly (i.e., measurements are not sensitive enough to some elastic constants, a variation of many percent of these ones yields a change in the measurement frequencies lower than the measurements accuracy) and a modified identification procedure is thus proposed. Finally, this modified procedure is applied to different wood samples with a large density range, including 
softwood and hardwood, and particularly non-homogeneous wood species or with specific anatomical features.

\section{Materials and methods}

\section{Wood samples}

Thirteen samples of wood were tested, all belonging to different species. With this choice, there was the possibility to test the RUS method over a large range of densities, anatomical or specimen specific structural peculiarities (i.e., microfibril angle, rays width, pores distribution, grain angle, homogeneity, chemical composition, etc.) that can affect the elastic properties, but with only one sample per species (see Table 1). The samples were machined using a milling machine in a cubic geometry (approximately $20 \mathrm{~mm}$ side length) whose faces are as parallel as possible to the anatomical directions $R, T$ and $L$. Note that the faces are identified by the name of the direction normal to the considered face such that, for example, the $R$ face corresponds to the $L T$ anatomical plane (or radial plane) and the $L$ face to the $R T$ anatomical plane (or transverse plane, see Fig. 1).

Air dry density $\rho$ of all samples was assessed as the ratio between the mass, measured using a weighting scale (accuracy $\pm 0.01 \mathrm{~g}$ ), and their volume obtained through the dimension measurements. The samples dimensions were measured using a caliper (accuracy $\pm 10 \mu \mathrm{m}$ ) in 5 points per direction (middle and 4 corners of the considered faces) leading to a final uncertainty of $\pm 0.1 \mathrm{~mm}$. This leads to an estimated relative uncertainty for the density of $\pm 1.7 \%$ for each sample. Microfibril angles (MFA) were computed from diffraction patterns obtained with an X-ray diffractometer (Agilent Technologies Gemini S) using the $\mathrm{Cu} \mathrm{K} \alpha$ (wavelength $\lambda=0.154 \mathrm{~nm}$, operated at $50 \mathrm{kV}$ and $30 \mathrm{~mA}$ ) with a $0.8 \mathrm{~mm}$ collimator on an extracted piece of each cube after RUS measurements. The azimuth distribution of the (200) cellulose reflection was used for the determination of the MFA of each specimen using the improved Cave's method (Yamamoto et al. 1993). The anatomical characteristics of each species were taken from the literature knowledge (Schoch et al. 2004; Whealer 2011; Dünisch 2017), whereas the specimen structural peculiarities were directly observed on each sample. All measurements have been taken on the same

sample for each species in the RUS and US measurements room, at around $20^{\circ} \mathrm{C}$ and $40 \%$ RH (climatized room with basic split type air conditioning system without humidity control) after a stabilization period of many weeks. Moreover, each sample mass has been checked before and after the whole measurements session, to ensure that no significant variations of its moisture content were generated during the entire process. After all measurements, samples were dried and their moisture content during the measurements thus determined. Averaged values between 7 and $9 \%$ were obtained for all samples. 
Table 1 Measured wood species; specimen measured air dry $\left(\approx 20^{\circ} \mathrm{C}\right.$ and $\left.40 \% \mathrm{RH}\right)$ density and microfibril angle (MFA); wood homogeneity, usual anatomical characteristics (rays width and pores distribution) (Schoch et al. 2004; Whealer 2011; Dünisch 2017) and specimen structural peculiarities (grain angle or curly grain, ring curvature, ring width, etc.) that can affect the elastic properties

\begin{tabular}{|c|c|c|c|c|}
\hline Wood species & $\begin{array}{l}\text { Density } \\
\left(\mathrm{kg} \mathrm{m}^{-3}\right)\end{array}$ & $\operatorname{MFA}\left({ }^{\circ}\right)$ & Homogeneity & $\begin{array}{l}\text { Anatomy and } \\
\text { specimen peculiarities }\end{array}$ \\
\hline $\begin{array}{l}\text { Beech (Fs) } \\
\quad \text { Fagus sylvatica } \mathrm{L} \text {. }\end{array}$ & 717 & 14 & + & $\begin{array}{l}\text { Quite wide rays, diffuse } \\
\text { porous, low grain angle, } \\
\text { ring curvature }\end{array}$ \\
\hline $\begin{array}{l}\text { Black locust ( } \mathrm{Rp}) \\
\quad \text { Robinia pseudoacacia } \mathrm{L} .\end{array}$ & 720 & 20 & - & $\begin{array}{l}\text { Middle rays width, } \\
\text { ring porous }\end{array}$ \\
\hline $\begin{array}{l}\text { Boco (Bp) } \\
\text { Bocoa prouacensis Aubl. }\end{array}$ & 1340 & 9 & ++ & $\begin{array}{l}\text { Diffuse porous, } \\
\text { ring curvature, } \\
\text { very homogeneous }\end{array}$ \\
\hline $\begin{array}{l}\text { Holm oak (Qi) } \\
\text { Quercus ilex L. }\end{array}$ & 789 & 26 & - & $\begin{array}{l}\text { Wide rays, ring porous, } \\
\text { curly grain }\end{array}$ \\
\hline $\begin{array}{l}\text { Letterwood }(\mathrm{Bg}) \\
\text { Brosimum guianense } \\
\text { [Aubl.] Huber }\end{array}$ & 1144 & 12 & ++ & $\begin{array}{l}\text { Diffuse porous, } \\
\text { low grain angle, } \\
\text { ring curvature, high } \\
\text { amount of extractives }\end{array}$ \\
\hline $\begin{array}{l}\text { Marblewood/snakewood } \\
\text { (Zr) Zygia racemosa syn. } \\
\text { Marmoroxylon racemosum } \\
\text { [Ducke] Barneby \& Grimes }\end{array}$ & 1052 & 8 & - & $\begin{array}{l}\text { Wide rays, diffuse porous, } \\
\text { large grain heterogeneities }\end{array}$ \\
\hline $\begin{array}{l}\text { Poplar (Pd) Populus deltoides } \\
\quad \times \text { Populus trichocarpa 'I45-51' }\end{array}$ & 457 & 14 & ++ & $\begin{array}{l}\text { Small ray width, diffuse } \\
\text { porous, reference for low } \\
\text { density and homogeneous } \\
\text { wood }\end{array}$ \\
\hline $\begin{array}{l}\text { Roupala }(\mathrm{Rm}) \\
\quad \text { Roupala Montana Aubl. }\end{array}$ & 1006 & 12 & - & $\begin{array}{l}\text { Very wide rays, } \\
\text { diffuse porous }\end{array}$ \\
\hline $\begin{array}{l}\text { Simarouba }(\mathrm{Sa}) \\
\text { Simarouba amara Aubl. }\end{array}$ & 453 & 16 & ++ & $\begin{array}{l}\text { Diffuse porous, } \\
\text { homogeneous and low } \\
\text { density as poplar, high } \\
\text { grain angle }\end{array}$ \\
\hline $\begin{array}{l}\text { Cypress (Cs) } \\
\text { Cupressus sempervirens L. }\end{array}$ & 570 & 3 & + & Homogeneous softwood \\
\hline $\begin{array}{l}\text { Norway Spruce } 1\left(\mathrm{~Pa}_{1}\right) \\
\text { Picea abies [L.] Karst }\end{array}$ & 646 & 31 & ++ & Compression wood \\
\hline $\begin{array}{l}\text { Norway Spruce } 2\left(\mathrm{~Pa}_{2}\right) \\
\text { Picea abies [L.] Karst }\end{array}$ & 476 & 9 & -- & $\begin{array}{l}\text { Normal wood for } \\
\text { soundboard: highly } \\
\text { anisotropic and } \\
\text { heterogeneous (high local } \\
\text { density gradient between } \\
\text { early- and late-wood) }\end{array}$ \\
\hline $\begin{array}{l}\text { Thuja articulata (Ta) } \\
\text { Tetraclinis articulata } \\
\text { [Vahl] Mast. }\end{array}$ & 610 & 25 & & Large ring, ring curvature \\
\hline
\end{tabular}




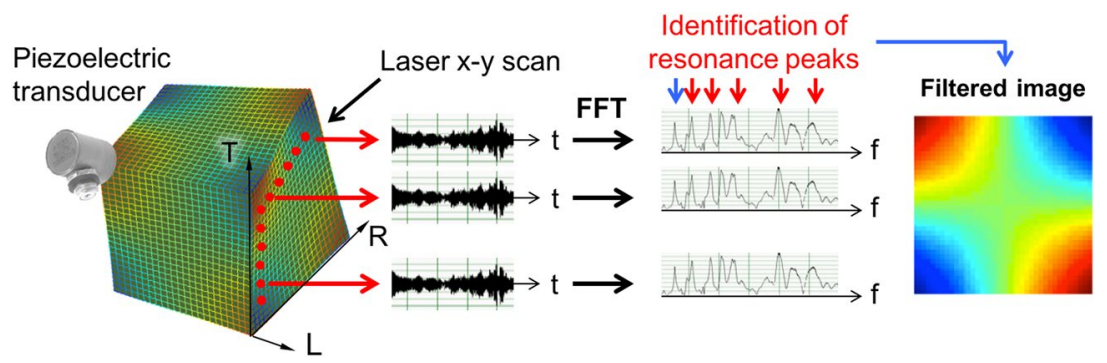

Fig. 1 Resonant Ultrasound Spectroscopy experimental setup and protocol for the measured $L$ face $(R T$ anatomical, or transverse, plane)

\section{Resonant Ultrasound Spectroscopy (RUS) experimental setup}

\section{Excitation of the cube with a specific multi-harmonic signal}

The experimental setup and protocol is presented in Fig. 1. The sample was put on a low-density polyurethane foam $\left(26 \mathrm{~kg} \mathrm{~m}^{-3}\right)$ block $\left(13.5 \times 25 \times 25 \mathrm{~mm}^{3}\right)$ and the ultrasonic excitation was provided by an Olympus C133-RM $(2.25 \mathrm{MHz})$ transducer "just" in contact with one corner of the sample, i.e., with a negligible applied load, and coupled with a honey droplet with the aim to excite the maximum number of free resonance frequencies (Longo et al. 2012). An optimized multi-harmonic excitation signal was created numerically using MATLAB software, so that its Fourier's spectrum is flat (Guillaume et al. 1991; Longo et al. 2008). This means that all frequencies were injected in the wood cube with almost the same energy. In detail, the excitation signal was a compressed multi-sine wave (time period $10 \mathrm{~ms}$, number of points 25,000, energy lines between 5 and $150 \mathrm{kHz}$ ) (Longo et al. 2012). Thus, an arbitrary wave generator (Agilent 33220A) continuously sent out the compressed multi-sine signal, with a frequency resolution of $100 \mathrm{~Hz}$, to the ultrasonic transducer in contact with the cube corner. The frequency range could be adapted, depending on the sample characteristics (stiffness, acoustic impedance or attenuation).

\section{Data acquisition and conditioning}

The sample surface, covered with a silver reflective tape, was investigated with a Scanning Laser Doppler Vibrometer (SLDV) that was synchronized with the function generator. Two step motors (Newport Corporation) have been attached to the laser head of a Polytec OFV-505 system allowing the scanning of the sample surface using LabVIEW software. Generally, $40 \times 40$ point maps of the normal displacement to the measured surface were recorded. It may be here noticed that, to reduce the computation time of the identification procedure, the resolution of the theoretical images was generally reduced to $20 \times 20$ pixels, using a linear interpolation thanks to the interp2 function of MATLAB software, without significantly affecting the quality of the final result. In order to increase the signal to noise ratio, 150 acquisitions over a period of $10 \mathrm{~ms}$ were performed at each point and averaged leading to a total 
data matrix of $40 \times 40 \times$ number of points of the temporal signal acquired by the velocimeter. In each point, the temporal out-of-plane displacement is then acquired and the modulus of the Fast Fourier transform was then computed. At a given resonant frequency, where the modulus amplitude is maximum, the spatial evolution exactly represents the mode shape (see Fig. 1). In order to collect more free resonant frequencies, and to make mode identification and pairing more straightforward, both $R$ and $L$ faces were measured consecutively. The $T$ face was not taken into account as it has usually been found that it provides no significant additional information, for example, the $T$ face spectrum has no additional resonant frequencies compared to the two other ones.

\section{Inverse identification of the elastic constants}

In a previous study (Longo et al. 2012), results obtained using RUS on a beech sample without taking the mode shapes into account were successfully compared to values from the literature and to some obtained by ultrasonic velocimetry. However, some mispositioning or swapping of the modes may appear as the viscoelastic damping of wood [e.g., quality factor usually around 30-100 (Brémaud et al. 2011)] causes the resonant peaks to overlap and quite a huge number of modes can completely disappear (Bernard et al. 2014). This made it hard to know which of the numerous theoretically computed resonant modes and frequencies correspond to the measured ones, even during the iterative steps of the identification process. In other words, computed modes may be assigned to the wrong measured free resonant frequency, leading to mode swapping and wrong inverse identification. This step, usually called frequency or mode pairing, is all the most difficult if the initial guess of the stiffness coefficients is badly known. Different solutions have been proposed in the literature (Bernard et al. 2014, 2015). In the present case, where a lot of modes were missed experimentally, the conclusion is drawn that it is necessary to take into account, in the inversion process, the pairing of the theoretical mode shapes with the experimental ones measured on some faces of the sample. In particular, this will allow the definition of an error function to be minimized during the inversion process. Scanning Laser Vibrometer (SLDV), and/or holographic techniques, can be used to experimentally determine the sample modes shapes (Vorobyev et al. 2016). In this paper, it is proposed to use the following steps for the identification:

1. Initial guess of the stiffness coefficients $C_{i j}$ using Guitard and El Amri (1987)'s regression laws knowing the sample density $\rho$,

2. Direct problem: all the theoretical modes and frequencies are computed in the measurement frequency range using the RUS program from Fig (2008) from $C_{i j}$, $\rho$ and the wood cube dimensions.

3. Eigenmode pairing between each measured mode $\Psi_{\mathrm{m}}$ and computed theoretical ones $\Psi_{\mathrm{c}}\left(C_{i j}\right)$ is performed by maximizing the correlation $\otimes$ in amplitudes and partial gradients along $x$ and $y$ (e.g., $\Psi_{\mathrm{m}}^{n} \otimes \Psi_{\mathrm{c}}^{n}=1$ if $\Psi_{\mathrm{m}}^{n}=\Psi_{\mathrm{c}}^{n}$ and 0 if $\Psi_{\mathrm{m}}^{n}$ is completely different in shape from $\Psi_{\mathrm{c}}^{n}$ ): 


$$
c_{n}=\Psi_{\mathrm{m}}^{n} \otimes \Psi_{\mathrm{c}}^{n}\left(C_{i j}\right)+\frac{1}{2}\left[\frac{\partial \Psi_{\mathrm{m}}^{n}}{\partial x} \otimes \frac{\partial \Psi_{\mathrm{c}}^{n}\left(C_{i j}\right)}{\partial x}+\frac{\partial \Psi_{\mathrm{m}}^{n}}{\partial y} \otimes \frac{\partial \Psi_{\mathrm{c}}^{n}\left(C_{i j}\right)}{\partial y}\right],
$$

for each measured face. Taking the gradients into account allows discriminating between very close theoretical mode shapes compared to a considered measured one (for example, see measured modes 1 and 5 in Fig. 3 where the $c_{n}$ values are almost equal for the associated theoretical modes if the gradients are not considered, i.e., taking the gradients into account increases the relative difference by a factor of two in that case). This procedure is performed each time an elastic constant is modified, namely at each step of the following minimization of the error function during the identification process.

4. Error function is computed using both the error in frequency and that in the mode shapes. These two parameters are linked, in the following expression of the correlation coefficient, through a weighting coefficient $k$ :

$$
\Delta=\sum_{n} \frac{\left|f_{\mathrm{m}}^{n}-f_{\mathrm{c}}^{n}\left(C_{i j}\right)\right|}{f_{\mathrm{m}}^{n}}+k \sum_{n}\left[2-c_{n}^{R}-c_{n}^{L}\right] \text {, }
$$

where $k$ has been set so that the ratio between the two terms of the above equation is between 5 and 10 times in favor of the frequency error (empirical estimation after many identification tests). The minimization process of $\Delta$ is then performed thanks to the lsqnonlin function of MATLAB software.

5. To reach a robust solution, the relative sensitivity $\frac{\Delta f_{m} / f_{m}}{\Delta X_{i} / X_{i}}$ of the measured mode $m$ to each elastic coefficient $X_{i}$ (e.g., $X_{i}=E_{\mathrm{T}}$ or $G_{\mathrm{TL}}$ or $\left.v_{\mathrm{RT}}\right)$ is studied. The identification protocol is thus divided into several stages in a decreasing sensitivity scheme (Grimsel 1998; Farzbod and Hurley 2012).

This scheme and the different steps have been tested and optimized on the beech sample and then applied to a large density range of wood samples.

\section{Results and discussion}

\section{Results on beech}

All the procedure has first been tried and tuned on the same beech sample as in Longo et al. (2012). The obtained average spectra of the four corners of the sample on the $R$ and $L$ faces are reported in Fig. 2 and the corresponding clearly identified measured mode shapes in Figs. $3 a$ and $b$, respectively. The frequency of these clearly identified mode shapes is reported as crosses on the frequency axis in Fig. 2. The initial theoretical mode shapes and frequencies computed, using the initial guess estimated from the sample density using Guitard and El Amri (1987)'s regression 


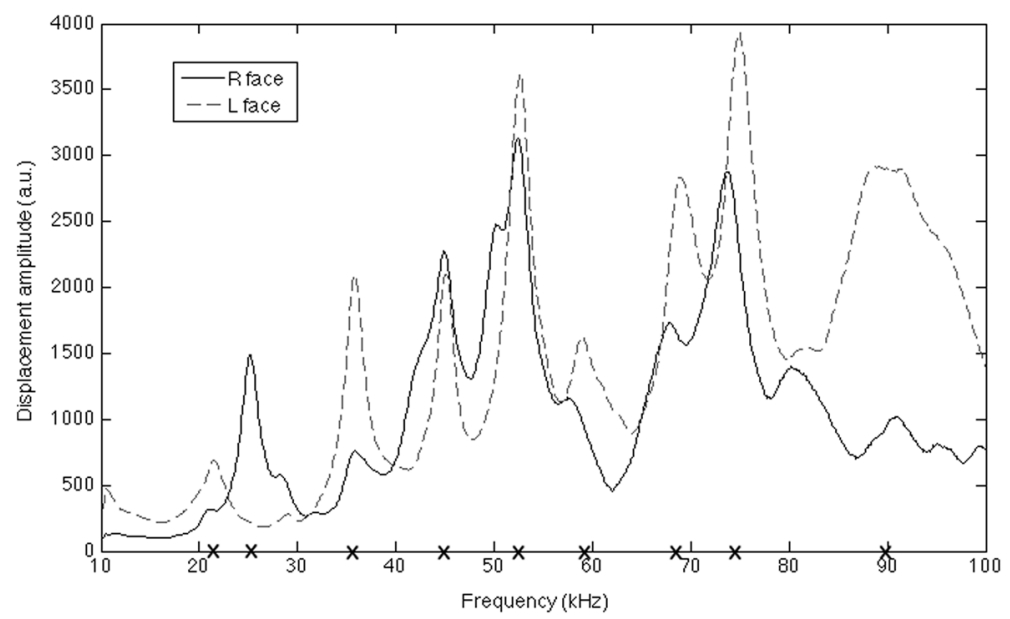

Fig. 2 Average spectra of the four corners of the beech cube sample for the measured $R$ and $L$ faces. Crosses on the frequency axis correspond to the clearly identified modes in Fig. 3

laws (see values in square brackets in Tables 2, and 3 in Supplementary data), paired with these measured modes are given in Figs. $3 \mathrm{c}$ and $\mathrm{d}$ for the $R$ and $L$ faces, respectively. One can see that there are less mode shapes (nine at all) than peaks on the spectrum. Indeed, some of the resonances identified as a peak on the spectrum in Fig. 2 do not have a clear mode shape while compared to all the initially computed theoretical ones, they have thus been dismissed. This could most probably be due to peaks overlapping. Moreover, for some modes, especially at the highest frequencies, one can see in Fig. 2 that the frequency on the $R$ and $L$ faces can differ up to $1 \mathrm{kHz}$. This is expected due to difference in the dynamic response of the cube with respect to the face in contact with the low density plastic foam block and the ultrasonic (excitation) transducer. Indeed, as the wood material is anisotropic, the impedance of each face is different, especially between the $R$ or $T$ face and the $L$ face.

A sensitivity analysis (see step 5 of the identification procedure) of the free resonance frequencies to the different elastic constants has been done (Fig. 4). It shows that the measured modes possess a high sensitivity to the shear moduli $G_{i j}$, a moderate one to the radial $E_{\mathrm{R}}$ and tangential $E_{\mathrm{T}}$ moduli and low one to the Poisson's ratio $\nu_{\mathrm{RT}}$ but almost no sensitivity to the longitudinal modulus $E_{\mathrm{L}}$. Moreover, these modes are not sensitive at all to the Poisson coefficients $v_{\mathrm{LR}}$ and $v_{\mathrm{LT}}$. The three last parameters, namely $E_{\mathrm{L}}, v_{\mathrm{LR}}$ and $v_{\mathrm{LT}}$, will then be very difficult to identify accurately and robustly with the current data. As a consequence, in the inversion scheme, $v_{\mathrm{LR}}$ and $\nu_{\mathrm{LT}}$ are fixed thanks to the values given by Guitard and El Amri (1987)'s regression laws. $E_{\mathrm{L}}$ is estimated from ultrasound velocity measurements of $C_{\mathrm{LL}}$, done with the procedure described in Longo et al. (2012). Note that the difference between $E_{\mathrm{L}}$ and $C_{\mathrm{LL}}$ is almost always lower than $10 \%$ in wood. Ultrasound velocity measurements have been used for estimating the other diagonal terms of the stiffness tensor too and are given in Supplementary data. Then, $v_{\mathrm{LR}}, v_{\mathrm{LT}}$ and $E_{\mathrm{L}}$ are not used in the following identification procedure. Moreover, this procedure is done in three steps. First, the 


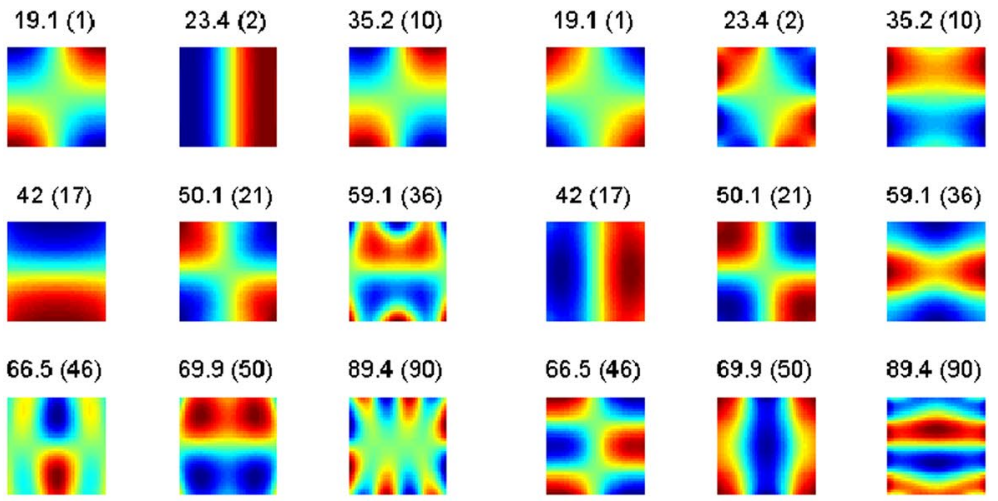

(a)

(b)
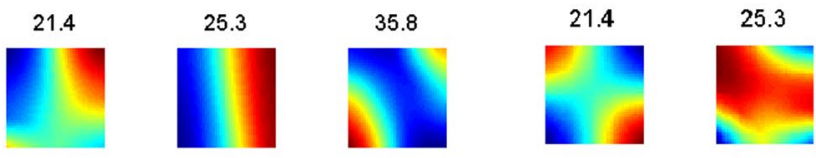

35.8
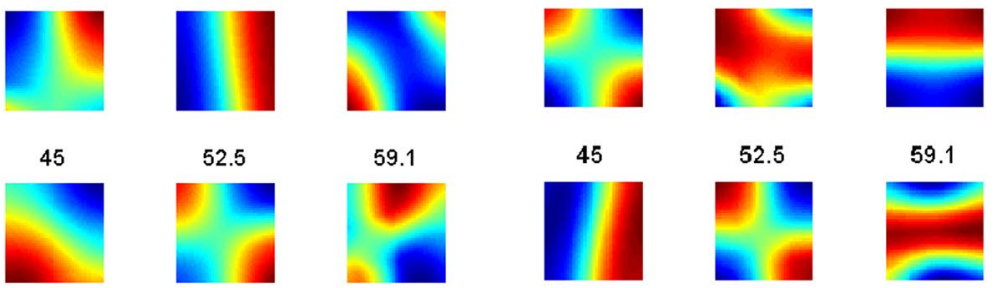

59.1

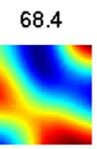

74.4
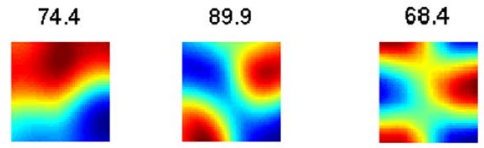

74.4

89.9

(c)

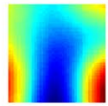

(d)
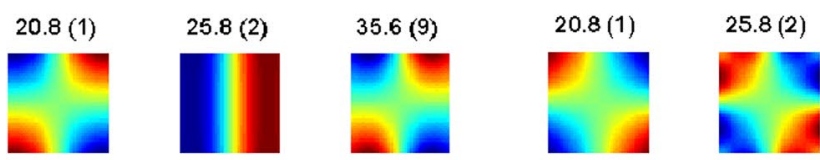

$35.6(9)$
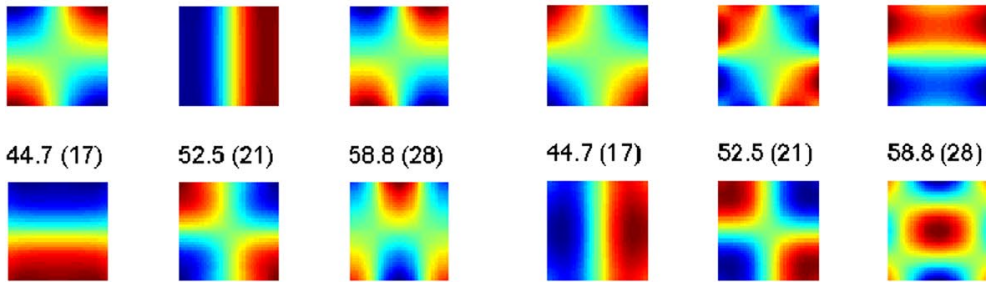

$58.8(28)$

$44.7(17)$

52.5 (21)

58.8 (28)
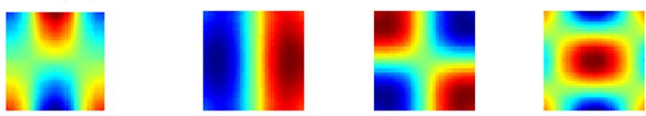

$58.8(44)$

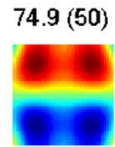

$91.2(83)$
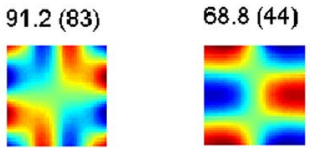

(e)

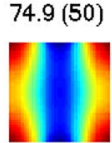

$91.2(83)$

(f)

Fig. 3 Mode shapes and resonant frequencies (in $\mathrm{kHz}$ ) measured (c, d), computed ones paired using the initial guess elastic constants estimated using Guitard and El Amri (1987) (a, b), and final computed ones after identification (e, f) on $R$ and $L$ faces, respectively. Values in parentheses correspond to the theoretically computed mode number 
Table 2 Results of the identification on different species using RUS data measurements for all the elastic constants (moduli in $\mathrm{GPa}$ ), except $E_{\mathrm{L}}$ that is taken constant and estimated through ultrasound velocity measurements, are given in the first line with the estimation from Guitard and El Amri (1987)'s regression laws in square brackets

\begin{tabular}{|c|c|c|c|c|c|c|c|}
\hline Sample & $E_{\mathrm{R}}$ & $E_{\mathrm{T}}$ & $E_{\mathrm{L}}(\mathrm{US})$ & $v_{\mathrm{RT}}$ & $G_{\mathrm{TL}}$ & $G_{\mathrm{RL}}$ & $G_{\mathrm{RT}}$ \\
\hline \multirow[t]{2}{*}{ Beech (Fs) } & $2.7[2.0]$ & $1.2[1.2]$ & 19.1 [15.9] & $0.79[0.70]$ & $1.10[1.1]$ & $1.59[1.4]$ & $0.53[0.4]$ \\
\hline & $1.5-2.2$ & $0.6-1.2$ & $9.2-19.4$ & $0.56-0.74$ & $0.76-1.13$ & $0.98-1.61$ & $0.35-0.50$ \\
\hline Longo et al. (2012) & 2.5 & 1.3 & 17.9 & 0.69 & 1.0 & 1.4 & 0.5 \\
\hline \multirow[t]{2}{*}{ Black locust (Rp) } & $2.5[2.1]$ & $1.9[1.2]$ & $16.2[16.0]$ & $0.58[0.67]$ & $1.55[1.1]$ & $1.62[1.4]$ & $0.68[0.4]$ \\
\hline & $2.0^{\mathrm{a}}$ & $1.6^{\mathrm{a}}$ & $13.5-19.8$ & $0.71^{\mathrm{a}}$ & $1.31^{\mathrm{a}}$ & $1.70^{\mathrm{a}}$ & 0.66 \\
\hline \multirow[t]{2}{*}{ Boco (Bp) } & $5.5[4.8]$ & $4.3[3.8]$ & $32.2[30.5]$ & $0.63[0.60]$ & $3.15[2.4]$ & $2.70[2.9]$ & $1.82[1.3]$ \\
\hline & $3.5^{\mathrm{b}}$ & - & - & - & - & - & - \\
\hline \multirow[t]{2}{*}{ Holm oak (Qi) } & $3.3[2.3]$ & $1.7[1.4]$ & $12.7[17.6]$ & $0.61[0.66]$ & $1.27[1.2]$ & $1.93[1.6]$ & $0.85[0.5]$ \\
\hline & $1.2-3.5$ & $0.6-1.3$ & $5.3-20.6$ & $0.64^{\mathrm{a}}$ & $0.7-1.7$ & $0.8-2.1$ & $0.3-1.0$ \\
\hline \multirow[t]{2}{*}{ Letterwood (Bg) } & $4.1[3.8]$ & $2.1[2.7]$ & $26.8[25.8]$ & $0.76[0.63]$ & $2.39[2.0]$ & $2.30[2.4]$ & $1.24[1.0]$ \\
\hline & - & - & $21.6-23.2$ & - & - & - & - \\
\hline \multirow{2}{*}{$\begin{array}{l}\text { Marblewood Snake- } \\
\text { wood }(\mathrm{Zr})\end{array}$} & $3.1[3.4]$ & $2.2[2.4]$ & $25.9[23.6]$ & $0.40[0.64]$ & $2.02[1.8]$ & $1.50[2.2]$ & $0.84[0.9]$ \\
\hline & - & - & - & - & - & - & - \\
\hline \multirow[t]{2}{*}{ Poplar (Pd) } & $1.5[1.1]$ & $0.5[0.6]$ & $11.7[10.0]$ & $0.68[0.69]$ & $0.70[0.6]$ & $0.67[0.8]$ & $0.17[0.2]$ \\
\hline & $0.7-1.2$ & $0.2-0.5$ & $6.8-12.4$ & $0.70-0.88$ & $0.40-0.90$ & $0.60-1.00$ & $0.10-0.20$ \\
\hline \multirow[t]{2}{*}{ Roupala (Rm) } & $3.5[3.2]$ & $2.9[2.2]$ & $22.8[22.6]$ & $0.55[0.64]$ & $1.41[1.7]$ & $2.00[2.1]$ & $1.16[0.8]$ \\
\hline & - & - & - & - & - & - & - \\
\hline \multirow[t]{2}{*}{ Simarouba (Sa) } & $0.9[1.1]$ & $0.8[0.5]$ & $10.4[9.9]$ & $0.70[0.70]$ & $0.80[0.6]$ & $1.13[0.8]$ & $0.22[0.2]$ \\
\hline & $1.2^{\mathrm{a}}$ & $0.7^{\mathrm{a}}$ & $7.1-11.8$ & $0.70^{\mathrm{a}}$ & $0.70^{\mathrm{a}}$ & $0.90^{\mathrm{a}}$ & $0.10^{\mathrm{a}}$ \\
\hline \multirow[t]{2}{*}{ Cypress (Cs) } & $1.6[1.2]$ & $1.3[0.8]$ & $14.1[18.1]$ & $0.20[0.48]$ & $1.11[0.9]$ & $1.22[1.1]$ & $0.22[0.1]$ \\
\hline & $1.7^{\mathrm{a}}$ & $1.2^{\mathrm{a}}$ & $11.2-13.2$ & $0.63^{\mathrm{a}}$ & $1.0^{\mathrm{a}}$ & $1.12^{\mathrm{a}}$ & - \\
\hline \multirow{2}{*}{$\begin{array}{l}\text { Norway Spruce } 1 \\
\quad\left(\mathrm{~Pa}_{1}\right)\end{array}$} & $2.3[1.5]$ & $1.1[1.0]$ & $8.6[21.2]$ & $0.52[0.48]$ & $1.17[0.9]$ & $1.74[1.3]$ & $0.24[0.1]$ \\
\hline & - & - & $3.0-9.8$ & - & $1.6^{\mathrm{a}}$ & - & - \\
\hline \multirow{2}{*}{$\begin{array}{l}\text { Norway Spruce } 2 \\
\quad\left(\mathrm{~Pa}_{2}\right)\end{array}$} & $1.4[1.1]$ & $0.9[0.7]$ & $14.2[14.2]$ & $0.63[0.48]$ & $0.70[0.8]$ & $0.71[0.9]$ & $0.05[0.09]$ \\
\hline & $0.4-1.8$ & $0.4-1.2$ & $8.1-17.0$ & $0.21-0.54$ & $0.5-0.9$ & $0.6-1.0$ & $0.01-0.07$ \\
\hline \multirow[t]{2}{*}{ Thuja (Ta) } & $2.0[1.4]$ & $1.3[0.9]$ & $12.7[19.8]$ & $0.54[0.48]$ & $1.20[0.9]$ & $1.56[1.2]$ & $0.44[0.12]$ \\
\hline & - & - & $13.8^{\mathrm{a}}$ & - & - & - & - \\
\hline
\end{tabular}

The second (or even third) line corresponds to literature data (Arnould et al. 2010; Bader et al. 2012, 2017; Bardet and Gril 2002; Brabec et al. 2017; Brémaud et al. 2013; Bucur and Archer 1984; Bucur 2006; Borst et al. 2012; El Mouridi et al. 2011; Fang et al. 2008; Garab et al. 2010; Gindl 2002; Guitard and El Amri 1987; Hering et al. 2012; Keunecke et al. 2007, 2008, 2011; Ozyhar et al. 2013a, b; Ruelle et al. 2007, 2011; Scholz et al. 2007; Sliker 1988, 1989; Timell 1986; Forest Products Laboratory 2010; Zhang and Sliker 1991) where ${ }^{a}$ stands for only one reference value available, ${ }^{b}$ for only one reference value available in the green state and - for no data available. Measurements were taken at $\approx 20^{\circ} \mathrm{C}$ and $40 \% \mathrm{RH}$

error function is minimized through the adjustment of the shear moduli only and taking only the most sensitive modes to these elastic constants into account. Second, the error function is minimized through the adjustment of $E_{\mathrm{R}}, E_{\mathrm{T}}$ and $v_{\mathrm{RT}}$ only and taking only the most sensitive modes to these elastic constants into account. Finally, 


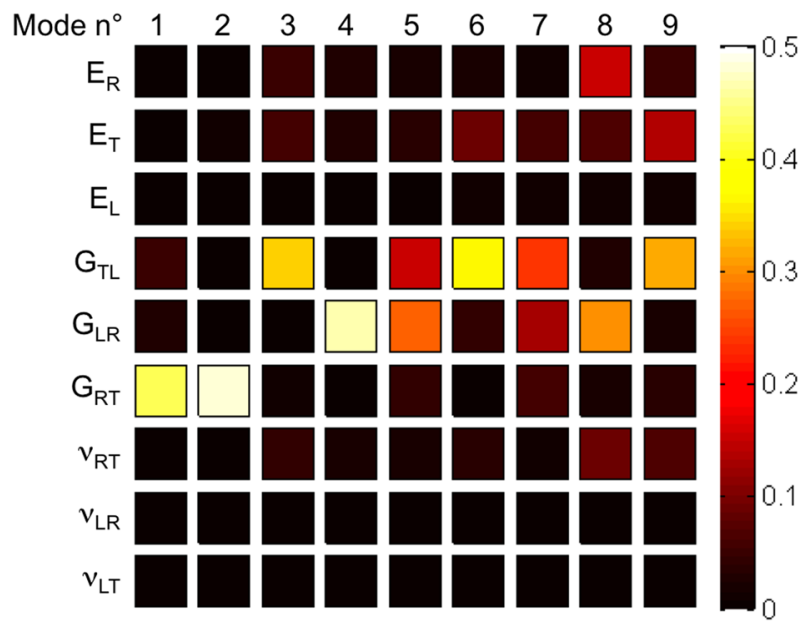

Fig. 4 Relative sensitivity $\frac{\Delta f_{m} / f_{m}}{\Delta X_{i} / X_{i}}$ of the measured modes $m$ to the elastic coefficients $X_{i}$ (e.g., $X_{i}=E_{\mathrm{T}}$ or $G_{\mathrm{TL}}$ or $\left.v_{\mathrm{RT}}\right)$, as defined in step 5 of the identification procedure

a global fit is performed on these five elastic constants. This procedure is repeated until stabilization of the considered elastic constants, namely less than $1 \%$ variation from one iteration to the next. Usually between three to five iterations are needed.

The final solution, given in Figs. $3 \mathrm{e}$ and $\mathrm{f}$ and in Table 2, is obtained with a mean error in frequency of about $1 \%$ and a relative difference with the parameters identified by ultrasonic velocimetry (see Supplementary data) of 3\%. Moreover, these results are in agreement with data from the literature, see Table 2 (and Table 3 in Supplementary data). It can be noted that some small differences can be noticed with the set of data given in Longo et al. (2012). A robustness test has been done by doing the inverse identification 10 times using, as initial guess, the elastic constants of the first identification that have been modified randomly by $10 \%$ (normal distribution). The resulting standard deviation, between 0.6 and $1.8 \%$, is similar for all shear moduli that confirms these elastic constants are identified robustly. For the last three other elastic constants, the resulting standard deviation is higher, i.e., between 6 and $7 \%$. This shows that, for a given elastic constant, the higher the sensitivity of the associated mode(s), the higher the confidence in its identified value. A last test was done on the effect of the resonance frequency measurements. For that purpose, each measured resonance frequency has been modified randomly by $\pm 0.5 \mathrm{kHz}$ (compared to the frequency measurement step of $0.1 \mathrm{kHz}$ ). This range of $1 \mathrm{kHz}$ corresponds to the sometimes observed mismatch between the resonance frequency measured on a given face compared to the other one (see Fig. 2). For all the identified elastic constants, this leads to a relative variation lower than $5 \%$. Note that the whole procedure (measurements and identification) takes, in its current state of development, around 2 to $4 \mathrm{~h}$ per sample. Significant time could be saved in the future during the measurement by: improving the laser motorization stage speed, feedback and trajectory; changing the kind of scanning system (e.g., rotary mirror); reducing the number of 


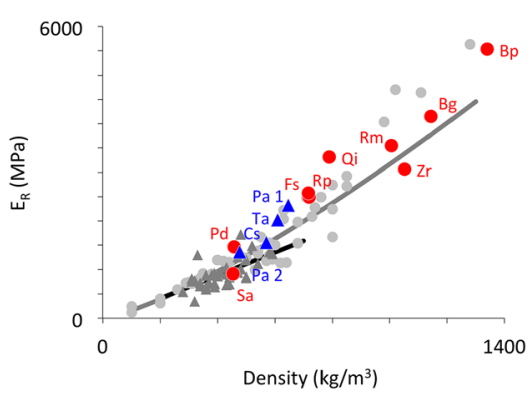

(a)

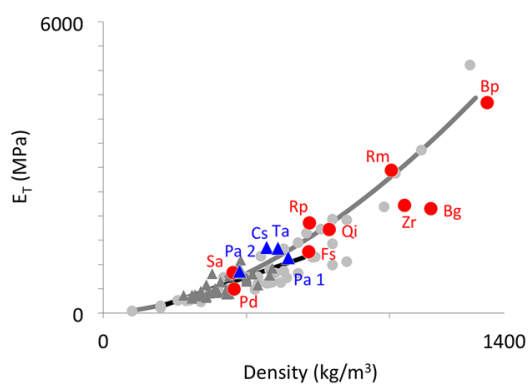

(c)

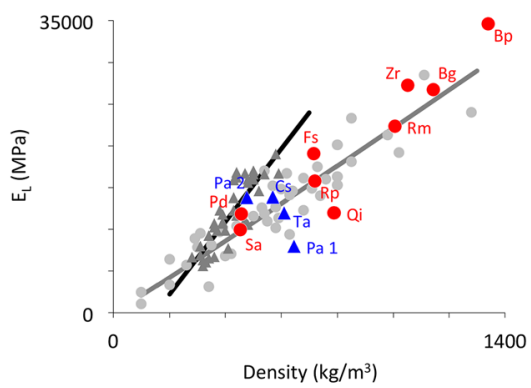

(e)

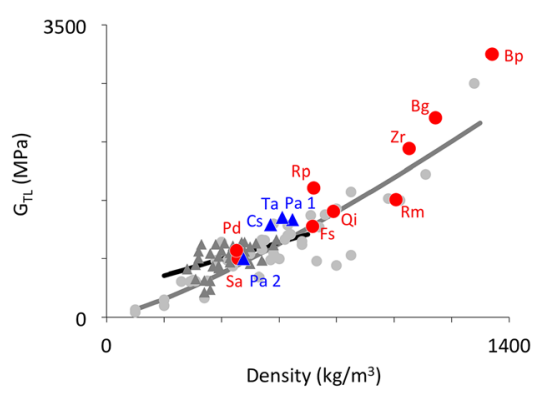

(b)

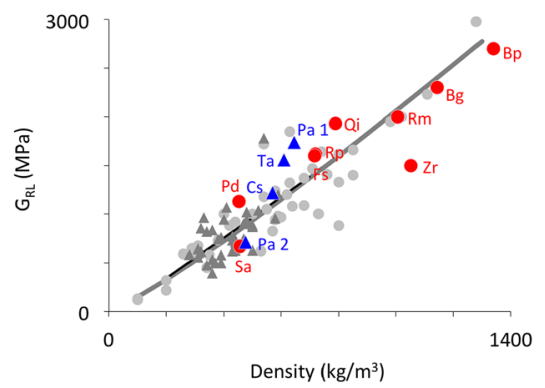

(d)

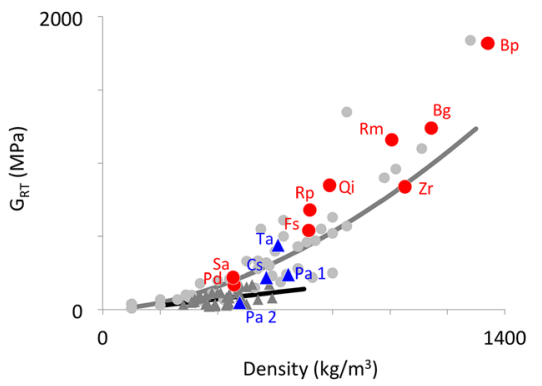

(f)

Fig. 5 Measured hardwood: red (dark gray in black and white) filled circles $(\mathrm{Fs}=\mathrm{Beech}, \mathrm{Rp}=\mathrm{Black}$ locust, $\mathrm{Bp}=$ Boco, Qi = Holm oak, Bg = Letterwood, $\mathrm{Zr}=$ Marblewood, $\mathrm{Pd}=$ Poplar, $\mathrm{Rm}=$ Roupala, $\mathrm{Sa}=$ Simarouba), measured softwood: blue (black in black and white) filled triangles $(\mathrm{Cs}=$ Cypress, $\mathrm{Pa}_{1}=$ Norway spruce $1(\mathrm{CW}), \mathrm{Pa}_{2}=$ Norway spruce $2(\mathrm{NW}), \mathrm{Ta}=$ Thuja articulata $)$, light gray filled circles: hardwood data used in Guitard and El Amri (1987), dark gray filled triangles: softwood data used in Guitard and El Amri (1987), dark gray line: Guitard and El Amri (1987)'s regression law for hardwood, black line: Guitard and El Amri (1987)'s regression law for softwood (colour figure online)

measurement points (Mesnil and Ruzzene 2016) or even by being able to avoid the scanning process (Bernard et al. 2014, 2015). The identification step time could be reduced too by developing a dedicated and optimized minimization algorithm. 


\section{Applications to a large density range of wood samples}

In this part, the identification procedure described above is applied to different wood samples, hardwood and softwood species, that yield (quite) a large range of density and anatomical characteristics (see Table 1). Sensitivity analysis has been done for all samples and yields almost the same map as in Fig. 4 with a high sensitivity to all the shear moduli, more or less sensitivity to $E_{\mathrm{R}}$, a reduced one to $E_{\mathrm{T}}$ and a very limited one or almost nothing at all to $v_{\mathrm{RT}}$. The number of clearly identified and measured modes varies between seven in the worst case, for the poplar (Pd) sample, to fifteen in the best case, for the black locust (Rp) sample, with an average of nine, like the beech (Fs) sample, to ten modes. In all cases, almost the first half of the measured modes are the same but are generally very different for the highest frequencies. The goal is thus to compare the current results to those obtained by Guitard and El Amri (1987)'s regression laws, used for the initialization of the identification procedure. These laws yield an order of magnitude of elastic moduli, taking the major effect of the density into account only (i.e., no effect of the MFA or other structural features like vessels or rays). Note that density, temperature and moisture content are able to explain $80 \%$ of the intra-specific variability of a normal clear wood but fails to describe variability inside a tree (juvenile wood, early-/late-wood, reaction wood, ...) (Guitard and Gachet 2004). The best regression obtained by these regression laws was for $E_{\mathrm{L}}$ followed by $E_{\mathrm{R}}, G_{\mathrm{RL}}$ and $G_{\mathrm{TL}}$, then $E_{\mathrm{T}}$ and finally, the less "accurate", $G_{\mathrm{RT}}$ with a coefficient of variation ratio (CVR) around $50 \%$. This last shear modulus is the one where RUS is the most sensitive (see Fig. 4) and that is why RUS has been used previously in wood (Schubert et al. 2006). Here, different species are compared. They have, among other anatomical characteristics, different chemical composition (e.g., cellulose, hemicellulose, lignin and extractives content), but the assumption was made that this will not mainly affect the elastic properties. It is important to remember that $E_{\mathrm{L}}$ has been measured through ultrasonic velocity measurements. Note that it was not possible to measure species with density lower than around $300 \mathrm{~kg} \mathrm{~m}^{-3}$. This could be due to a too high attenuation or dispersion in such kinds of sample that leads to obtain frequency spectra without any clear peaks nor clear mode shapes. Results are given in Table 2 (and Table 3 in Supplementary data) and Fig. 5. For all samples, the mean final error in frequency $[\Delta / n$ when $k=0$ in Eq. (2)] is in general below $1 \%$ and equal to $1.8 \%$ at the maximum for Simarouba (Sa). It is important to keep in mind that only one sample per species has been measured here and thus the current analysis must be confirmed by additional measurements on other samples.

The first set of results to analyze is those related to "homogenous" wood species samples (e.g., diffuse porous, small ray width) with classical low MFA: beech (Fs), boco $(\mathrm{Bp})$, letterwood $(\mathrm{Bg})$, poplar $(\mathrm{Pd})$, simarouba $(\mathrm{Sa})$ and cypress $(\mathrm{Cs})$. In that case, one can see in Fig. 5 that results are generally in good agreement with values predicted by Guitard and El Amri (1987)'s regression laws except for the highest densities, i.e., above $900 \mathrm{~kg} \mathrm{~m}^{-3}$. Indeed, these authors did not have that much data at such high density for adjusting their laws and the current results are in good agreement with their data available at such high density (see the light gray filled circle in Fig. 5). However, letterwood (Bg) sample has a very low $E_{\mathrm{T}}$ modulus and 
it seems that its only particularity is its high amount of extractives that is not known to have any significant effect on the elastic properties or anisotropy (Se Golpayegani et al. 2012). So the origin of this low value is not understood for now, but it could be due to a too low sensitivity of the inversion algorithm to this modulus in that case (see Fig. 4). Cypress (Cs) sample data are quite close to those of the regression laws except for $E_{\mathrm{T}}$ again and, especially $E_{\mathrm{L}}$, but this last value is obtained by US measurements and in agreement with the literature (see Table 2).

Next is another homogenous wood but with a (very) high MFA: Norway spruce $1\left(\mathrm{~Pa}_{1}\right)$ is a compression wood compared to Norway spruce $2\left(\mathrm{~Pa}_{2}\right)$ that is a normal wood used for musical instruments soundboard, with a low MFA but high local density gradient between early and late wood. It is important to note that, due to the high MFA, the elastic and shear moduli are very different from the initial guess in the case of Norway spruce compression wood $\left(\mathrm{Pa}_{1}\right)$, but it does not lead to specific difficulties for the identification. One can see in Fig. 5 that the effect of this high MFA on the elastic moduli is in agreement with the literature (Bader et al. 2012), i.e., a lower longitudinal modulus $\left(E_{\mathrm{L}}\right)$ and higher transverse ones (especially $E_{\mathrm{R}}$ but not $E_{\mathrm{T}}$ in the present case) compared to Guitard and El Amri's regression laws or normal wood $\mathrm{Pa}_{2}$. The effect of MFA on shear moduli is not that well documented in the literature but, according to Bader et al. (2012), it appears here that it increases $G_{\mathrm{RL}}$ and, especially, $G_{\mathrm{TL}}$ but also probably slightly $G_{\mathrm{RT}}$. Moreover, these effects are confirmed by US measurements (see Table 3 in Supplementary data) and the thuja sample (Ta) where similar tendencies are observed (both RUS and US). Norway spruce normal wood $\left(\mathrm{Pa}_{2}\right)$ has all its elastic and shear moduli values very close to the ones estimated using the regression law, in spite of its high local density gradient between early- and late-wood, in agreement with the literature (Bader et al. 2012) (see Tables 2 and 3 in Supplementary data).

The last four species, black locust (Rp), holm oak (Qi), marblewood (Zr) and roupala $(\mathrm{Rm})$, are more heterogeneous with grain angle, wide rays and diffuse or ring porous structure and sometimes a high MFA. Two of them, black locust (Rp) and holm oak (Qi), have a ring porosity, middle width to wide rays, high MFA, and even curly grain for oak. As for Norway spruce $1\left(\mathrm{~Pa}_{1}\right)$, the effect of the high MFA and curly grain seems clearly visible for holm oak (Qi) in Fig. 5 with a lower $E_{\mathrm{L}}$, higher $E_{\mathrm{R}}, G_{\mathrm{RL}}$ and $G_{\mathrm{RT}}$ but apparently no effect on the other elastic constants. Except for $G_{\mathrm{TL}}$ and $G_{\mathrm{RT}}$, these tendencies cannot be observed for the black locust sample (Rp) whose elastic constants are very close to the Guitard and El Amri's estimates. On the other side, marblewood $(\mathrm{Zr})$ and roupala $(\mathrm{Rm})$ have both a diffuse porosity and wide to very wide rays with a quite low MFA, but they do not yield similar tendencies whatever the elastic constants (see Fig. 5). $E_{\mathrm{T}}$ and $G_{\mathrm{RL}}$ are particularly low for marblewood, whereas all the elastic constants are quite close to the Guitard and El Amri's estimates for roupala $(\mathrm{Rm})$, except for $G_{\mathrm{RT}}$ that is higher. Micromechanical models have been developed (Bader et al. 2017; de Borst et al. 2012) to understand the effect of the different anatomical specificities on the elastic constants at the macroscopic scale. High ray content and low vessel content should be beneficial for the shear stiffness $G_{\mathrm{LR}} \cdot G_{\mathrm{LT}}$ should decrease for both increasing vessel and ray fractions. Large ray cell bundles should lower $E_{\mathrm{T}}$. A high ray content positively affects stiffness in the tangential direction, i.e., lower $E_{\mathrm{L}}$ but higher 
$E_{\mathrm{R}}$, whereas the arrangement of vessels in a continuous ring in ring-porous species should decrease $E_{\mathrm{R}}$. The rolling shear stiffness $G_{\mathrm{RT}}$ is expected to be higher for a diffuse porous structure than for a ring porous one. In general, a ring porous arrangement results in lower shear stiffness, irrespective of the particular shear plane. All in all, each of these anatomical or structural peculiarities can affect the elastic properties positively or negatively and can thus counterbalance, for example, opposite effect of a high ray content and a ring porous structure on $E_{\mathrm{R}}$. This makes the results and interpretation less obvious. Even if some tendencies in the current results seem to fit with the micromechanical models for some elastic constants, no clear global tendencies can be drawn here. More data are necessary, with samples repetitions, to properly conclude.

Eventually, all the obtained results are generally in agreement with the available literature data, reported in Table 2 (and Table 3 in Supplementary data), even for the Poisson's ratio $v_{\mathrm{RT}}$ except for cypress $(\mathrm{Cs})$ and Norway spruce normal wood $\left(\mathrm{Pa}_{2}\right)$. These Poisson's ratios data are to be used with caution as the sensitivity of the measured modes is very low in almost all cases. This low sensitivity to the Poisson's ratios has for consequences that their value has almost no effect on the inversion procedure, i.e., a wrong Poisson's ratio does not change significantly the other elastic constants identified. In conclusion, the identification procedure proposed has successfully identified $E_{\mathrm{R}}, E_{\mathrm{T}}$ (to a lesser extent) and especially $G_{\mathrm{TL}}, G_{\mathrm{RL}}$ and $G_{\mathrm{RT}}$ whatever the specificity of the hardwood or softwood samples and for a density ranging from 450 to $1350 \mathrm{~kg} \mathrm{~m}^{-3}$. Note, however, that the softwood samples are generally more difficult to measure (less clear measured modes) and thus to identify. This is expected to be due to the higher difference between early- and late-wood density compared to hardwoods.

\section{Conclusion}

First, this paper proposed the improvement of a Resonant Ultrasound Spectroscopy setup for the measurement of the elastic constant of an unique cubic wood sample (Longo et al. 2012) by using a specific continuous wave as excitation signal and adding the measurement of the mode shapes of the free resonant modes in addition to their frequencies. This was included in the iterative numerical procedure to solve the inverse problem for identifying components of the stiffness tensor of the wood material. This new procedure was tested on a beech wood sample. The gain of using the mode shapes in the inverse identification procedure was demonstrated to be particularly necessary in that case, especially for pairing each measured frequency with its corresponding theoretically predicted one, as viscoelastic damping causes the resonant peaks to overlap and/or disappear. The evaluation of the sensitivity of each measured resonant mode to each component of the stiffness tensor allowed moreover for finding the limits of the robustness of the procedure. It is very sensitive to all of the three shear elastic moduli that can thus be robustly identified, the elastic moduli $E_{\mathrm{R}}$ and, to a lesser extent, $E_{\mathrm{T}}$ can be identified but with a reduced robustness. Poisson's ratio $v_{\mathrm{RT}}$ can sometimes be identified but with a very limited robustness. The two other Poisson's ratios and the last elastic moduli $E_{\mathrm{L}}$ cannot be identified at all. Thus, a modified iterative procedure was proposed, based on each mode's relative 
sensitivity to each elastic constant, where $E_{\mathrm{L}}$ is measured before by using ultrasonic velocimetry measurements and the Poisson's ratios fixed equal to values predicted by Guitard and El Amri (1987)'s regression laws. It was applied successfully to different wood samples, whose density ranged from 450 to $1350 \mathrm{~kg} \mathrm{~m}^{-3}$, including softwood and hardwood, and particularly non-homogeneous wood species or with specific anatomical features. Wood samples with lower density were not measurable due probably to a too high damping. Whatever the specificities or the heterogeneities of the different samples, the identification procedure yielded reliable elastic constants that were compared to the literature and the values predicted by Guitard and El Amri's regression laws. This demonstrates the ability of RUS for measuring different elastic constants that are not so easy to measure by other methods, especially on the same sample. The next development step would be to be able to identify $E_{\mathrm{L}}$ and all the Poisson's ratios using the RUS data. This requires to have access to more modes, especially those that are sensitive to these elastic constants. This could be obtained by using other procedures that are able to handle peaks overlap (Bernard et al. 2014, 2015) and parallelepipedic shape optimization (Bernard et al. 2011) coupled with theoretical computation of the frequencies of the most relevant modes to focus the measurements in the best frequency range. Another way could be based on the coupling between ultrasound velocimetry methods and RUS. This will require to better understand what is exactly measured during ultrasound velocimetry methods on such kind of samples and understand the origin of the symmetric measurement mismatch for the shear moduli (Bader et al. 2017; Ozyhar et al. 2013b). The resulting method could be applied to revisit and improve the Guitard and El Amri's regression laws and wood databases, as the measurement of all the elastic constants could be made on the same sample. The effect of moisture content (from dry to green and saturated state) on all the elastic constants of the same sample could be studied too. Moreover, it could take into account sample defaults or structural peculiarities like anatomical directions disorientation, ring curvature, curly grain, nodes... Thus, it will allow for handling the wood natural variability and having a better prediction of the elastic constants of a part made of wood knowing its density (and its mean MFA) for civil and mechanical engineering applications with a high added value and/or complex mechanical loading. Applications to tree biomechanics on miniaturized green samples, for example, to study the change in anisotropy ratio during the wood maturation, could be considered. Moreover, this method is very useful for the study of archeological wood (Vorobyev et al. 2016) as the number of required sample is very limited and it could be easily adapted to smaller samples, mainly limited by the sample heterogeneities and higher damping due to higher natural frequencies. In all cases, a last step would be to take the viscosity (damping) into account for extrapolating such data obtained at medium (RUS) to high (US) frequencies at frequencies in agreement with civil engineering or tree biomechanics applications (i.e., around some $\mathrm{Hz}$ ).

Acknowledgements The authors would like to thank Professor Gilles Despaux and Franck Augereau (IES, Univ. Montpellier, CNRS) for their precious help in the conception of the instrumentation of the Scanning Laser Doppler Vibrometer and Tancrède Alméras (LMGC, Univ. Montpellier, CNRS) and Arie van der Lee (IEM, Univ. Montpellier, CNRS) for the X-ray diffraction measurements. Financial support from Labex NUMEV (Univ. Montpellier, CNRS) and StressInTrees project (ANR-12-BS09-0004 funded by the French National Research Agency ANR) is gratefully acknowledged. 


\section{References}

Arnould O, Stürzenbecher R, Bardet S, Hofstetter K, Guibal D, Amusant N, Pizzi A (2010) Mechanical potential of eco-OSB produced from durable and nondurable species and natural resins. Holzforschung 64(6):791-798

Bader TK, Hofstetter K, Eberhardsteiner J, Keunecke D (2012) Microstructure-stiffness relationships of common yew and Norway spruce. Strain 48(4):306-316

Bader TK, Eberhardsteiner J, De Borst K (2017) Shear stiffness and its relation to the microstructure of 10 European and tropical hardwood species. Wood Mater Sci Eng 12(2):82-91

Bardet S, Gril J (2002) Modelling the transverse viscoelasticity of green wood using a combination of two parabolic elements. C R Mécanique 330(8):549-556

Bernard S, Grimal Q, Haupert S, Laugier P (2011) Assessment of anisotropic elasticity of small bone samples with resonant ultrasound spectroscopy: attenuation does not prevent the measurements. In: IEEE International Ultrasonics Symposium, pp 1599-1602. https://doi.org/10.1109/ ULTSYM.2011.0397

Bernard S, Grimal Q, Laugier P (2014) Resonant ultrasound spectroscopy for viscoelastic characterization of anisotropic attenuative solid materials. J Acoust Soc Am 135(5):2601-2613

Bernard S, Marrelec G, Laugier P, Grimal Q (2015) Bayesian normal modes identification and estimation of elastic coefficients in resonant ultrasound spectroscopy. Inverse Probl 31(6):065 010

Brabec M, Lagaña R, Milch J, Tippner J, Sebera V (2017) Utilization of digital image correlation in determining of both longitudinal shear moduli of wood at single torsion test. Wood Sci Technol 51(1):29-45

Brancheriau L, Baillères H (2002) Natural vibration analysis of clear wooden beams: a theoretical review. Wood Sci Technol 36(4):347-365

Brémaud I, Cabrolier P, Gril J, Clair B, Gerard J, Minato K, Thibaut B (2010) Identification of anisotropic vibrational properties of Padauk wood with interlocked grain. Wood Sci Technol 44(3):355-367

Brémaud I, Gril J, Thibaut B (2011) Anisotropy of wood vibrational properties: dependence on grain angle and review of literature data. Wood Sci Technol 45(4):735-754

Brémaud I, Ruelle J, Thibaut A, Thibaut B (2013) Changes in viscoelastic vibrational properties between compression and normal wood: roles of microfibril angle and of lignin. Holzforschung 67(1):75-85

Bruno L, Poggialini A (2005) Elastic characterization of anisotropic materials by Speckle interferometry. Exp Mech 45(3):205-212

Bruno L, Felice G, Pagnotta L, Poggialini A, Stigliano G (2008) Elastic characterization of orthotropic plates of any shape via static testing. Int J Solids Struct 45(3-4):908-920

Bucur V (2006) Acoustics of wood, 2nd edn. Springer, Berlin

Bucur V, Archer RR (1984) Elastic constants for wood by an ultrasonic method. Wood Sci Technol 18(4):255-265

Bucur V, Rasolofosaon P (1998) Dynamic elastic anisotropy and nonlinearity in wood and rock. Ultrasonics 36(7):813-824

Dahl KB, Malo KA (2009) Linear shear properties of spruce softwood. Wood Sci Technol 43(5-6):499-525

Dahmen S, Ketata H, Ben Ghozlen M, Hosten B (2010) Elastic constants measurement of anisotropic Olivier wood plates using air-coupled transducers generated Lamb wave and ultrasonic bulk wave. Ultrasonics 50(4-5):502-507

De Borst K, Bader TK, Wikete C (2012) Microstructure-stiffness relationships of ten European and tropical hardwood species. J Struct Biol 177:532-542

Delaunay T, Le Clézio E, Guennou M, Dammak H, Pham Thi M, Feuillard G (2008) Full tensorial characterization of single PZN-12\%PT crystal by resonant ultrasound spectroscopy. IEEE Trans Ultrason Ferroelectr Freq Control 55(2):476-488

Dünisch O (2017) Relationship between anatomy and vibration behaviour of softwoods and hardwoods. IAWA J 38(1):81-98

El Mouridi M, Laurent T, Brancheriau L, Arnould O, Famiri A, Hakam A, Gril J (2011) Searching for material symmetries in the burr wood of thuja by a direct contact ultrasonic method on spherical samples. Maderas-Cienc tecnol 13(3):285-296

Fang CH, Guibal D, Clair B, Gril J, Liu YM, Liu SQ (2008) Relationships between growth stress and wood properties in poplar I-69 (Populus deltoides Bartr. cv. "Lux" ex I-69/55). Ann For Sci 65(3):307 
Farzbod F, Hurley DH (2012) Using eigenmodes to perform the inverse problem associated with resonant ultrasound spectroscopy. IEEE Trans Ultrason Ferroelectr Freq Control 59(11):2470-2475

Fig M (2008) Resonant ultrasound spectroscopy (RUS). Matlab® Central. http://fr.mathworks.com/matlabcentral/fileexchange/11399-resonant-ultrasound-spectroscopy--rus-. Accessed 15 Nov 2017

Forest Products Laboratory (2010) Wood handbook-wood as an engineering material. U.S. Department of Agriculture, Forest Service, Forest Products Laboratory, Madison, WI, General Technical Report FPL-GTR-190

François M, Geymonat G, Berthaud Y (1998) Determination of the symmetries of an experimentally determined stiffness tensor: application to acoustic measurements. Int J Solids Struct 35(31-32):4091-4106

Garab J, Keunecke D, Hering S, Szalai J, Niemz P (2010) Measurement of standard and off-axis elastic moduli and Poisson's ratios of spruce and yew wood in the transverse plane. Wood Sci Technol 44(3):451-464

Gindl W (2002) Comparing mechanical properties of normal and compression wood in Norway spruce: the role of lignin in compression parallel to the grain. Holzforschung 56(4):395-401

Gonçalves R, Trinca AJ, Cerri DGP (2011) Comparison of elastic constants of wood determined by ultrasonic wave propagation and static compression test. Wood Fiber Sci 43(1):64-75

Gonçalves R, Trinca AJ, Pellis BP (2014) Elastic constants of wood determined by ultrasound using three geometries of specimens. Wood Sci Technol 48(2):269-287

Grimsel M (1998) Computer-aided identification of mechanical wood properties. In: Kurjatko S, Kúdela J (eds) Wood structure and properties'98, Arbora Publishers, Zvolen, pp 185-192

Guillaume P, Schoukens J, Pintelon R, Kollar I (1991) Crest-factor minimization using nonlinear Chebyshev approximation methods. IEEE Trans Instrum Meas 40(6):982-989

Guitard D, El Amri F (1987) Modèles prévisionnels de comportement élastique tridimensionnel pour les bois feuillus et les bois résineux (Predictive models of tridimensional elastic behavior of hardwoods and softwoods). Ann Sci For 44(3):335-358 (in French)

Guitard D, Gachet C (2004) Paramètres structuraux et/ou ultrastructuraux facteurs de la variabilité intraarbre de l'anisotropie élastique du bois (Structural and/or ultrastructural parameters factors of intratree wood elastic anisotropy variability). Ann For Sci 61:129-139 (in French)

Hassel B, Berard P, Modén C, Berglund L (2009) The single cube apparatus for shear testing-full-field strain data and finite element analysis of wood in transverse shear. Compos Sci Technol 69:877-882

Hering S, Keunecke D, Niemz P (2012) Moisture-dependent orthotropic elasticity of beech wood. Wood Sci Technol 46(5):927-938

Keunecke D, Sonderegger W, Pereteanu K, Lüthi T, Niemz P (2007) Determination of Young's and shear moduli of common yew and Norway spruce by means of ultrasonic waves. Wood Sci Technol 41:309-327

Keunecke D, Hering S, Niemz P (2008) Three-dimensional elastic behaviour of common yew and Norway spruce. Wood Sci Technol 42(8):633-647

Keunecke D, Merz T, Sonderreger W, Schnider T, Niemz P (2011) Stiffness moduli of various softwood and hardwood species determined with ultrasound. Wood Mater Sci Eng 6(3):91-94

Kohlhauser C, Hellmich C (2012) Determination of Poisson's ratios in isotropic, transversely isotropic, and orthotropic materials by means of combined ultrasonic-mechanical testing of normal stiffnesses: Application to metals and wood. Eur J Mech A Solid 33:82-98

Kohlhauser C, Hellmich C, Vitale-Brovarone C, Boccaccini AR, Rota A, Eberhardsteiner J (2009) Ultrasonic characterisation of porous biomaterials across different frequencies. Strain 45(1):34-44

Laghdir A, Fortin Y, De La Cruz CM, Hernández RE (2008) Development of a technique to determine the 3D elasticty tensor of wood as applied to drying stress modeling. Maderas-Cienc tecnol 10(1):35-44

Laux D, Ferrandis JY, Leveque G, Gatt JM (2006) Elastic properties of composites: periodical homogenisation technique and experimental comparison using acoustic microscopy and resonant ultrasonic spectroscopy. Ultrasonics 45:104-112

Longo R, Vanherzeele J, Vanlanduit S, Guillaume P (2008) Underwater visualization of multi-input interleaved multisine wave fronts for ultrasonic testing of bones specimens using Laser Doppler vibrometry. In: 8th international conference on vibration measurements by laser techniques: advances and applications, proceedings SPIE, vol 70980T. https://doi.org/10.1117/12.803032

Longo R, Delaunay T, Laux D, El Mouridi M, Arnould O, Le Clézio E (2012) Wood elastic characterization from a single sample by resonant ultrasound spectroscopy. Ultrasonics 52:971-974 
Majano-Majano A, Fernandez-Cabo JL, Hoheisel S, Klein M (2012) A test method for characterizing clear wood using a single specimen. Exp Mech 52:1079-1096

Mesnil O, Ruzzene M (2016) Sparse wavefield reconstruction and source detection using compressed sensing. Ultrasonics 67:94-104

Migliori A, Sarrao JL, Visscher WM, Bell TM, Lei M, Fisk Z, Leisure R (1993) Resonant ultrasound spectroscopic technics for measurement of the elastic moduli of solids. Physica B 183:1-24

Obataya E, Ono T, Norimoto M (2000) Vibrational properties of wood along the grain. J Mater Sci 35:2993-3001

Ozyhar T, Hering S, Niemz P (2013a) Moisture-dependent orthotropic tension-compression asymmetry of wood. Holzforschung 67(4):395-404

Ozyhar T, Hering S, Sanabria SJ, Niemz P (2013b) Determining moisture-dependent elastic characteristics of beech wood by means of ultrasonic waves. Wood Sci Technol 47(2):329-341

Reiterer A, Stanzl-Tschegg SE (2001) Compressive behaviour of softwood under uniaxial loading at diffrent orientations to the grain. Mech Mater 33:705-715

Ruelle J, Beauchêne J, Thibaut A, Thibaut B (2007) Comparison of physical and mechanical properties of tension and opposite wood from ten tropical rainforest trees from different species. Ann For Sci 64:503-510

Ruelle J, Beauchêne J, Yamamoto H, Thibaut B (2011) Variations in physical and mechanical properties between tension and opposite wood from three tropical rainforest species. Wood Sci Technol 45(2):339-357

Schoch W, Heller I, Schweingruber FH, Kienast F (2004) Wood anatomy of central European species. Online version: www.woodanatomy.ch. Accessed 15 Nov 2017

Scholz G, Liebner F, Koch G, Bues CT, Günther B, Bäucker E (2007) Chemical, anatomical and technological properties of Snakewood [Brosimum guianense (Aubl.) Huber]. Wood Sci Technol 41:673-686

Schubert SI, Gsell D, Dual J, Motavalli M, Niemz P (2006) Rolling shear modulus and damping factor of spruce and decayed spruce estimated by modal analysis. Holzforschung 60:78-84

Se Golpayegani A, Brémaud I, Gril J, Thevenon MF, Arnould O, Pourtahmasi K (2012) Effect of extractions on dynamic mechanical properties of white mulberry (Morus alba). J Wood Sci 58:153-162

Seichepine JL (1980) Mise au point d'une méthode expérimentale destinée à l'identification de la matrice des complaisances élastiques de solides anisotropes : Application aux matériaux bois (Development of an experimental method for the identification of the elastic compliance matrix of anisotropic solids: application to wood materials). PhD thesis, I.N.P. de Lorraine, Nancy (in French)

Sliker A (1988) A method for predicting non-shear compliances in the RT plane of wood. Wood Fiber Sci 20(1):44-55

Sliker A (1989) Measurement of the smaller Poisson's ratios and related compliances for wood. Wood Fiber Sci 21(3):252-262

Timell T (1986) Compression wood in gymnosperms. Springer, Berlin

Vázquez C, Gonçalves R, Bertoldo C, Baño V, Vega A, Crespo J, Guaita M (2015) Determination of the mechanical properties of Castanea sativa Mill. using ultrasonic wave propagation and comparison with static compression and bending methods. Wood Sci Technol 49(3):607-622

Visscher WM, Migliori A, Bell TM, Reinert RA (1991) On the normal modes of free vibration of homogeneous and anisotropic elastic objects. J Acoust Soc Am 90(4):2154-2161

Voigt W (1928) Lehrbuch der Kristallphysik (Textbook of crystal physics), reprint of the 1st edn. Teubner, Leipzig (in German)

Vorobyev A, Arnould O, Laux D, Longo R, van Dijk NP, Gamstedt EK (2016) Characterisation of cubic oak specimens from the Vasa ship and recent wood by means of quasi-static loading and resonance ultrasound spectroscopy (RUS). Holzforschung 70(5):457-465

Whealer EA (2011) Insidewood - a web resource for hardwood anatomy. IAWA J 32(2):199-211, online version: http://insidewood.lib.ncsu.edu/search. Accessed 15 Nov 2017

Yamamoto H, Okuyama T, Yoshida M (1993) Method of determining the mean microfibril angle of wood over a wide range by the improved Cave's method. Mokuzai Gakkaishi 39(4):375-381

Yoshihara H (2012) Off-axis Young's modulus and off-axis shear modulus of wood measured by flexural vibration tests. Holzforschung 66:207-213

Zhang W, Sliker A (1991) Measuring shear moduli in wood with small tension and compression samples. Wood Fiber Sci 23(1):58-68 


\section{Supplementary data}

Ultrasound velocimetry

Pulse measurements in transmission are performed in the $R(1), T(2)$ and $L$ (3) directions of the cubic sample using contact ultrasound transducers. With the knowledge of the ultrasound velocity in a given direction and the sample density, estimation of diagonal terms of the stiffness elastic tensor from $C_{11}$ to $C_{66}$ are then estimated. Given the specimen shape and dimensions compared to the wavelength of the ultrasound used and sensors diameter, velocities yield more probably an estimation of the stiffness tensor components $C_{i j}$ than the elastic Young's moduli.

$C_{11}\left(C_{R R}\right), C_{22}\left(C_{T T}\right)$ and $C_{33}\left(C_{L L}\right)$ are thus measured with longitudinal waves and $C_{44}\left(G_{T L}\right), C_{55}\left(G_{R L}\right)$ and $C_{66}\left(G_{R T}\right)$ with shear waves. The experimental set-up involved two pairs of contact transducers (Panametrics V103 for longitudinal velocities, center frequency: $1 \mathrm{MHz}$, diameter: $13 \mathrm{~mm}$ and Panametrics V151 for shear velocities, center frequency: $0.5 \mathrm{MHz}$, diameter: $26 \mathrm{~mm}$ ). These two ultrasonic sensors excited with a pulse generator were coupled to the sample with honey. The transmitted signals, captured by the receiving transducer were acquired 100 times by means of a digital oscilloscope (Lecroy WaveJet 334), and the data were averaged. The measuring session started recording the signal at the receiver without the sample (transmission within the surfaces of the transducers in contact, 100 recorded $50 \mu$ s signals in total) and then with the sample (100 recorded $50 \mu$ s signals for one measurement point). The transmission time through all the directions was estimated implementing a cross correlation between these two signals. Afterwards, from the mean thickness of the sample in the wave propagation direction, the sound velocities were derived. The six diagonal values of the stiffness elastic tensor measured on each sample are given in Table 3. 
Table 3: Results of the identification on different species using RUS data measurements for all the stiffness elastic constants (moduli in $\mathrm{GPa}$ ), except $C_{L L}$ that is taken constant and estimated through ultrasound velocity measurements, are given on the first line with the estimation from Guitard and El Amri (1987)'s regression laws in brackets. The second line corresponds to ultrasound velocimetry measurements. The third (or even fourth) line corresponds to literature data (see Table 2) where * stands for only one reference value available, ** other data available $\left(e . g ., E_{R}\right.$ instead of $C_{R R}$ or $\nu_{R T}$ instead of $\left.C_{R T}\right)$; $* * *$ inaccurate measurement. Measurements were done at $\approx 20^{\circ} \mathrm{C}$ and $40 \% \mathrm{RH}$.

\begin{tabular}{|c|c|c|c|c|c|c|c|c|c|}
\hline Sample & $C_{R R}\left(C_{11}\right)$ & $C_{T T}\left(C_{22}\right)$ & $C_{L L}\left(C_{33}\right)$ & $C_{R T}\left(C_{12}\right)$ & $C_{R L}\left(C_{13}\right)$ & $C_{T L}\left(C_{23}\right)$ & $G_{T L}\left(C_{44}\right)$ & $G_{R L}\left(C_{55}\right)$ & $G_{R T}\left(C_{66}\right)$ \\
\hline Beech (Fs) & $4.0[2.9]$ & $1.8[1.7]$ & $20.6[17.2]$ & $1.5[1.2]$ & $2.3[1.7]$ & $1.4[1.3]$ & $1.10[1.1]$ & $1.59[1.4]$ & $0.53[0.4]$ \\
\hline \multirow[t]{2}{*}{ US } & 3.6 & 1.8 & 20.6 & $-\quad[+3$ & $-\quad$ l & $-\quad[20]$ & 1.10 & 1.80 & 0.60 \\
\hline & $3.3-3.7$ & $1.4-2.2$ & $16.9-20.1$ & $1.4^{*}$ & $4.5^{*}$ & $2.9^{*}$ & $0.86-1.13$ & $1.24-1.61$ & $0.35-0.50$ \\
\hline Longo et al (2012) & 3.5 & 1.8 & 19.5 & 1.3 & 1.8 & 1.6 & 1.0 & & \\
\hline Black locust (Rp) & $3.6[3.0]$ & $2.7[1.8]$ & $17.5[17.3]$ & $1.7[1.2]$ & $2.2[1.7]$ & $1.9[1.3]$ & $1.55[1.1]$ & $1.62[1.4]$ & $0.68[0.4]$ \\
\hline US & 3.7 & 2.1 & $\begin{array}{l}17.5 \\
* *\end{array}$ & - & - & - & 1.58 & 1.78 & 0.64 \\
\hline \multirow{2}{*}{$\begin{array}{l}\text { Boco (Bp) } \\
\text { US }\end{array}$} & $9.0[7.3]$ & $7.0[5.7]$ & $36.4[34.1]$ & $4.8[3.7]$ & $6.0[4.6]$ & $5.1[4.0]$ & $3.15[2.4]$ & $2.70[2.9]$ & $1.82[1.3]$ \\
\hline & & & 36.4 & - & $-L^{2} \quad-1$ & - & $3.20^{\mathrm{L}}$ & 3.70 & 2.13 \\
\hline \multirow{2}{*}{$\begin{array}{l}\text { Holm oak (Qi) } \\
\text { US }\end{array}$} & $4.6[3.4]$ & $2.3[2.1]$ & $13.8[19.1]$ & $1.6[1.5]$ & $2.6[2.0]$ & $1.7[1.5]$ & $1.27[1.2]$ & $1.93[1.6]$ & $0.85[0.5]$ \\
\hline & 4.3 & 2.3 & 13.8 & $1-21$ & $-7-29$ & $20-25$ & 1.22 & 1.97 & 0.87 \\
\hline \multirow{3}{*}{$\begin{array}{l}\text { Letterwood (Bg) } \\
\text { US }\end{array}$} & $6.5[5.8]$ & $\begin{array}{l}1.6-3 \\
3.3[4.2]\end{array}$ & $\frac{10.1-20.0}{29.7[28.7]}$ & $\begin{array}{l}1-2.1 \\
2.7[2.9]\end{array}$ & $2.7-2.9$ & $\begin{array}{l}2.0-2.5 \\
2.6[3.1]\end{array}$ & $\begin{array}{l}0.7-1.7 \\
2.39[2.0]\end{array}$ & $\frac{0.0-2.1}{2.30[2.4]}$ & $\begin{array}{l}0.3-1.0 \\
1.24[1.0]\end{array}$ \\
\hline & 6.2 & 5.4 & 29.7 & (2) & ] & - & 2.3 & 2.0 & 1.35 \\
\hline & & 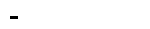 & & - & 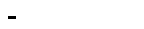 & - & the & 然 & \\
\hline \multirow{2}{*}{$\begin{array}{l}\text { Marblewood } \\
\text { Snakewood (Zr) } \\
\text { US }\end{array}$} & $3.6[5.2]$ & $2.6[3.6]$ & $28.8[26.1]$ & $1.1[2.5]$ & $2.0[3.2]$ & $1.6[2.6]$ & $2.02[1.8]$ & $1.50[2.2]$ & $0.84[0.9]$ \\
\hline & 3.1 & $3.6^{* * *}$ & 28.8 & - & - & - & 1.87 & 1.78 & 0.86 \\
\hline \multirow{3}{*}{$\begin{array}{l}\text { Poplar (Pd) } \\
\text { US }\end{array}$} & $1.8[1.5]$ & $0.6[0.8]$ & $12.4[10.6]$ & $0.4[0.6]$ & $0.9[0.8]$ & $0.4[0.6]$ & $0.70[0.6]$ & $0.67[0.8]$ & $0.17[0.2]$ \\
\hline & 1.9 & & 12.4 & - & - & - & 0.73 & 0.99 & 0.14 \\
\hline & 0.9 & $0.3-0.4$ & $5.8-9.7$ & ( & 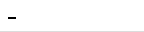 & - & $0.4-0.9$ & $0.6-1.0$ & $0.1-0.2$ \\
\hline \multirow{3}{*}{$\begin{array}{l}\text { Roupala (Rm) } \\
\text { US }\end{array}$} & $5.2[4.8]$ & $4.3[3.3]$ & $25.1[24.9]$ & $2.6[2.3]$ & $3.3[3.0]$ & $3.0[2.4]$ & $1.41[1.7]$ & $2.00[2.1]$ & $1.16[0.8]$ \\
\hline & 5.2 & 3.9 & 25.1 & - & - & - & 1.42 & 1.95 & 0.99 \\
\hline & - & - & 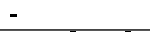 & - & & - & - & & \\
\hline \multirow{3}{*}{$\begin{array}{l}\text { Simarouba (Sa) } \\
\text { US }\end{array}$} & $1.8[1.5]$ & $1.6[0.7]$ & $11.0[10.5]$ & $1.2[0.6]$ & $1.2[0.8]$ & $0.9[0.6]$ & $0.80[0.6]$ & $1.13[0.8]$ & $0.22[0.2]$ \\
\hline & $1.5^{* * *}$ & $2.4^{* * * *}$ & 11.0 & 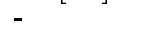 & - $-2+3$ & 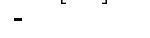 & 1.19 & 1.06 & 0.26 \\
\hline & $* *$ & $* *$ & $* *$ & - & - & - & $0.7^{*}$ & $0.9^{*}$ & $0.1^{*}$ \\
\hline \multirow{3}{*}{$\begin{array}{l}\text { Cypress (Cs) } \\
\text { US }\end{array}$} & $1.6[1.5]$ & $1.4[1.0]$ & $14.5[18.7]$ & $0.3[0.5]$ & $0.7[0.8]$ & $0.7[0.6]$ & $1.11[0.9]$ & $1.22[1.1]$ & $0.22[0.1]$ \\
\hline & $3.1^{* * *}$ & $2.4^{* * *}$ & & $-\bar{*}$ & $-\bar{x}$ & - & 1.09 & 1.33 & 0.19 \\
\hline & - & - & & $* *$ & ** & $* *$ & - & - & - \\
\hline \multirow{3}{*}{$\begin{array}{l}\text { Norway } \\
\text { Spruce } 1\left(\mathrm{~Pa}_{1}\right) \\
\text { US }\end{array}$} & $2.9[1.8]$ & $1.4[1.2]$ & $8.9[21.9]$ & $0.8[0.6]$ & $1.4[0.9]$ & $0.9[0.7]$ & $1.17[0.9]$ & $1.74[1.3]$ & $0.24[0.1]$ \\
\hline & 3.7 & 1.6 & 8.9 & - & - & - & 1.38 & 2.25 & 0.23 \\
\hline & $1.1^{*}$ & $0.8^{*}$ & $6.0^{*}$ & - & - & - & $1.6^{*}$ & - & - \\
\hline \multirow{3}{*}{$\begin{array}{l}\text { Norway } \\
\text { Spruce } 2\left(\mathrm{~Pa}_{2}\right) \\
\text { US }\end{array}$} & $1.9[1.3]$ & $1.2[0.8]$ & $14.6[14.6]$ & $0.8[0.4]$ & $1.0[0.7]$ & $0.8[0.5]$ & $0.70[0.8]$ & $0.71[0.9]$ & $0.05[0.09]$ \\
\hline & $1.6^{* * *}$ & $0.4^{* * *}$ & 14.6 & - & 1207 & - & 0.79 & 0.74 & 0.09 \\
\hline & $0.7-2.7$ & $0.3-1.7$ & $6.4-16.2$ & $0.9-1.5$ & $1.3-2.7$ & $0.6-1.4$ & $0.5-0.9$ & $0.6-1.0$ & $0.01-0.07$ \\
\hline \multirow{3}{*}{$\begin{array}{l}\text { Thuja (Ta) } \\
\text { US }\end{array}$} & $2.6[1.7]$ & $1.8[1.1]$ & $13.1[20.4]$ & $1.0[0.6]$ & $1.3[0.9]$ & $1.3[0.7]$ & $1.20[0.9]$ & $1.56[1.2]$ & $0.44[0.12]$ \\
\hline & 3.0 & & 13.1 & - & - & - & 1.21 & 1.98 & 0.48 \\
\hline & $2.5-4.2$ & $1.2-3.7$ & $10.3-14.3$ & - & - & - & & & \\
\hline
\end{tabular}

